\title{
Individual Cancer History
}

National Cancer Institute

\section{Source}

National Cancer Institute. Individual Cancer History. NCI Thesaurus. Code C18849.

A record of a patient's medical background regarding the occurrence of cancer and cancer-related problems. 